\begin{tabular}{|l|l|}
\hline Recibido / Received & 26 de septiembre de 2019 \\
\hline AcEPTAdo / AcEPTED & 10 de junio de 2020 \\
\hline PÁGinas / PAGes & De la 159 a la 163 \\
\hline
\end{tabular}

\title{
Imperiofilia y el populismo nacional-católico
}

\author{
Autor / Author \\ VIШACAÑAS, José Luis \\ Editorial / Publishing company \\ LENGUA DE TRAPO, Madrid 2019 \\ DOI: https://doi.org/10.32466/eufv-rel.2020.7.574.159-163
}

osé Luis Villacañas afirma haber interrumpido sus preocupaciones intelectuales para responder a uno de los libros de mayor éxito de los últimos años (algunos dirían al éxito más que al libro), el de María Elvira Roca Barea, Imperiofobia y leyenda negra. Roma, Rusia, Estados Unidos y el Imperio español (Siruela, Madrid, 2016). Su crítica es medular. No son discrepancias puntuales - cualquier lector informado no dejaría de tenerlas, dada la multitud de temas que trata Imperiofobia - ; Villacañas rechaza de raíz los planteamientos de Roca Barea. Caracterizando su pensamiento como populismo intelectual reaccionario, le recrimina reducir la historia moderna de Europa a un enfrentamiento, de raíz exclusivamente política, entre el catolicismo y el protestantismo; indica la carencia de estructura lógica en su obra, llena de contradicciones y, en último término, reducida a una mera acumulación impresionista de denuncias y quejas; lamenta la permanente falta de matices de un discurso maniqueo fundado en una especie de darwinismo nietzscheano. En principio, el objetivo de Roca Barea es analizar el hecho imperial, pero su libro no es otra cosa que una indisimulada y acrítica defensa de la obra imperial de España. Con brevedad se detiene en la historia de Estados Unidos - recuperando, con un punto de incongruencia nacido de la forma como analiza el conflicto católico-protestante, el tópico que subyace en la vieja obra de Philip W. Powell, Tree of Hate (1971) - y, casi de puntillas, pese al título del libro, trata el Imperio romano y la historia de Rusia. La primera gran crítica de Villacañas no puede ser eludida: ¿por qué Roca Barea ha ignorado la condición imperial de Gran Bretaña e, incluso, del Islam, así como las posibles semejanzas y comparaciones de estos últimos con el dominio imperial de la monarquía hispánica? Si pretendiese estudiar, como afirma, el hecho imperial y la oposición que despierta, estas omisiones serían incomprensibles. Quizá pueda explicarse el desinterés por las formas políticas islámicas, pero no que Gran Bretaña - presente en todo el libro - no sea considerada desde la misma perspectiva que las otras potencias imperia- 
les, sino como enemiga radical del Imperio español. Evidentemente, el objetivo de Roca Barea no es analizar el hecho imperial.

Es posible disentir con algunas tesis de Villacañas. Es lógico que la simplificación que Roca Barea hace del protestantismo le obligue a múltiples matizaciones, pero identificar, desde un punto de vista teológico, al luteranismo con un regreso a san Pablo (algo que, sin duda, es en su origen) y no con la ruptura - nacida de la espiritualidad angustiada y el pesimismo antropológico del monje agustino que han condicionado, por siglos, múltiples manifestaciones protestantes - de la tensión paradójica de la revelación es discutible; cierto que Villacañas ve con precisión cómo lo que podríamos llamar un pleito de frailes, lleno de profundidad, sinceridad y espiritualidad, se convierte, por interés y cerrilismo, en un cisma profundo con connotaciones políticas diversas y, cosa que Roca Barea parece no reconocer, lógicas. Por otra parte, Villacañas quizás exagera el peso negativo de la expulsión de los judíos y el establecimiento de la Inquisición en España; quizás lo exagera, pero las preguntas que apunta son capitales: ¿destruyeron la conciencia de comunidad en España? ¿Generaron una desconfianza radical de la comunidad al poder? ¿Esterilizaron al catolicismo español? ¿Frustraron la tradición historiográfica que nacía con Juan de Mariana?

Sin duda problemas abiertos al debate, pero mi coincidencia con Villacañas es anterior a todo esto y dicha coincidencia es lo que justifica esta recensión de una recensión. Su libro contiene una denuncia en torno a la manipulación del ser mismo de la Historia. Los historiadores tenemos una preocupación, casi obsesiva, en torno a la utilidad de nuestra disciplina; todo aquel que se aproxima a la historia sin reflexionar seriamente sobre el sentido y el método, no pasa de ser un aficionado. Algo me resulta evidente: sirva para lo que sirva la Historia (la mayúscula aquí es obligada), no sirve para eso para lo que la utiliza María Elvira Roca Barea, por mucho que pretenda responder a otros que la han utilizado en el mismo sentido.

Pero antes incluso de preguntarnos por el sentido de la historia, debemos detenernos en dos planteamientos de esta autora, que no han pasado inadvertidos al profesor Villacañas. Pese a cómo se presenta en la introducción de su obra -agnóstica profunda de tradición familiar masónica, que ve en las Bienaventuranzas un programa ético más bien lamentable-, Roca Barea parece identificar en toda su obra a la monarquía española con la causa católica, ignorando a otras potencias católicas - no pocas de ellas enfrentadas con España- y, muy especialmente a Roma. Dicha identificación es un grave error historiográfico - los intereses de España y de la Iglesia, como poder político y como realidad espiritual, no coincidieron nunca plenamente - y una inaceptable aberración teológica, que no se subsana porque Roca Barea reduzca todo el protestantismo -y, en consecuencia, el catolicismo- a su dimensión política. ¿Es, acaso, como ella pretende, una mera reacción «nacionalista» para imposibilitar el proyecto imperial de Carlos V?

La otra gran cuestión es la leyenda negra. No cabe negar la existencia de esta leyenda, ni su interés historiográfico, lo preocupante es el enfoque con el que algunos la abordan. Villacañas insiste en que es un fenómeno que no va más allá del siglo xVII (de Felipe II a la paz de Westfalia), vinculado a los Países Bajos; luego habrá opiniones negativas sobre España, pero 
no leyenda negra. No creo que pueda afirmarse esto de una forma tan tajante, pero más cerca de la verdad está esta tesis que la de aquellos que leen toda la historia de España, hasta el presente, como la de un ente incomprendido y golpeado por una enemistad universal e injusta, nacida de la envidia. La reflexión sobre la leyenda puede partir, como apunta Villacañas, de dos datos. Por un lado, la propaganda contra el poderoso lógicamente existe y existe siempre, pero ni lo explica todo ni cabe ignorar la paralela existencia de la propaganda orquestada por el poderoso, sea esta exitosa o no, ni tampoco que en el seno de las sociedades más fuertes existen, como en las débiles, posiciones ideológicas heterogéneas, nacidas de la conciencia que toda sociedad tiene de sus deficiencias, incoherencias e injusticias. Por otra parte, no cabe ignorar que el éxito de la llamada leyenda negra se vincula a la debilidad del proyecto político, no del poder, de la Monarquía hispánica.

A mí la leyenda negra me retrotrae a mi época de estudiante y las lecciones de los dos grandes maestros que enseñaban en el departamento de Historia de América de la Universidad Complutense, don José Manuel Pérez-Prendes y don Mario Hernández Sánchez-Barba, a los que recuerdo respondiendo, casi por gentileza, a las preguntas que algunos de mis condiscípulos les hicieron sobre este tema y cuya inmensa obra historiográfica fue permanentemente ajena a ese planteamiento y a esa temática; si la historia de España es valiosa e interesante, lo es en sí misma, no en una enfermiza reivindicación, donde todos son culpables e inocentes, amigos y enemigos.

Se pregunta el profesor Villacañas cuál debe ser la sana relación del ser humano con la historia y, en torno a este tema, redacta las mejores páginas de su libro, las que justifican el tiempo dedicado a escribirlo; comienzan con la bella afirmación de que se escribe historia para despedirse del pasado, consciente de que uno solo se despide de lo que ama. «El historiador, continua, quiere saber de qué se despide», cargando con todos los defectos del pasado y no recrearlo "de la manera que necesitamos nosotros para nuestra euforia»; "escribe para despedirse del pasado como forma de tenerlo dentro. Es un compromiso de recordar para no repetir. El efecto real de esta despedida no es sino una toma de distancia no del pasado, sino del presente» y, de esta forma, atender a la vida de forma saludable. Defiende una Historia escéptica que, generando un espacio para la libertad, «dibuja el pasado para mirar bien el presente y preparar el futuro».

En estos párrafos encuentro mi coincidencia con José Luis Villacañas.

La Historia, cuyo estudio responde a tres necesidades humanas vitales, tiene una función política, una función vinculada al desarrollo de la convivencia. Desde Heródoto, buscando las causas del mutuo enfrentamiento de griegos y persas, hasta las grandes revoluciones historiográficas del siglo pasado, un amplio número de investigadores - es decir, de historiadores, si nos acogemos a la etimología griega - ha insistido en la comprensión de la realidad como razón última de la Historia. Muchas veces he intentado explicar a mis alumnos que el ser humano está irremediablemente atrapado en una necesidad: su acción se fundamenta en la previsión y esta en el conocimiento de la realidad. He recurrido al ejemplo del enfermo de Alzheimer, el angustiado desmemoriado que no se atreve a moverse de su sillón porque no 
sabe dónde está ni cómo ha llegado a ese lugar en el que se encuentra; he recurrido al ejemplo de esa puerta cerrada de la que nada podemos imaginar al otro lado - nada, absolutamente nada - y nunca abriríamos porque la curiosidad no es suficiente para responder a la falta de previsión. Podríamos suponer que detrás de la puerta hay un dragón y saldríamos dispuestos a enfrentarnos con él; haríamos el ridículo, pero saldríamos. Si imaginamos nada, nunca abriríamos la puerta, incapaces de prever cómo actuar. La Historia cumple esa función: en la medida en la que comprendemos la realidad, somos capaces de realizar previsiones y actuar. Es una tarea difícil, es una tarea que en la aceleración de los cambios que ha caracterizado al mundo contemporáneo, se hace cada día más compleja, pero no menos necesaria.

Otros historiadores han pensado que la disciplina responde a la necesidad humana de cohesionar a la comunidad. Desde la más lejana antigüedad, hemos contado y recontado nuestras historias, asimilando ideales y proyectos, haciendo propias derrotas y victorias, olvidando frustraciones, con la intención, más o menos explícita, de constituir una comunidad con capacidad de supervivencia. Es fácil traer a la memoria la historiografía nacionalista, pero esta actitud no es exclusiva del nacionalismo, ni este sería el mejor ejemplo de lo que la Historia puede proporcionar. El nacionalismo -y bien ha identificado Villacañas, en esta ocasión, al nacionalismo catalán con los planteamientos de Roca Barea- es la identificación absoluta con un pasado considerando eterno y esencial, con la única pretensión de diferenciar amigo y enemigo, testimoniando la carencia más decisiva: el coraje de conocer, que es el elemento básico de Occidente.

Aquí es donde la tercera función de la Historia - o la tercera forma de aproximarse a su ejercicio - dota de toda su riqueza de posibilidad al esfuerzo por comprender la realidad y a la búsqueda de la identidad. Se trata de una función liberadora, que se basa en el escepticismo, en la duda como camino a la verdad, en el estudio como esfuerzo por enfrentarnos a nuestras propias creencias. Escribir historia escéptica, dice Villacañas, es como sentirse libre del pasado $y$, añado yo, solo cuando nos sentimos libres del pasado somos capaces de comprender la realidad y fundamentar, con grandeza de espíritu y no mezquindad, la cohesión.

De este modo, si el núcleo central de Imperiofobia - el análisis de la Leyenda negra en la estela, no mejorada, de Maltby - contiene análisis acertados e ideas interesantes, el resultado final se viene abajo por la pobreza de su marco teórico; el empeño en prolongar, y ahora sin argumentos sólidos, esa leyenda a lo largo de los siglos xIX, xx y xxI, y los objetivos de la autora. Estoy convencido de que Imperiofobia es, en definitiva, historiográficamente insostenible y políticamente rechazable (si el nacionalismo español solo puede ofrecer esta reconstrucción cadavérica resulta tan perverso como el catalanismo y, tristemente, tendrá mucho menos futuro), pero en lo que quizá no acierte Villacañas es en las motivaciones de Roca Barea y, por lo mismo, en la detección del género literario usado. ¿Es evidente identificarla con lo que Villacañas denomina populismo nacional-católico, apuntando, desde el subtítulo de su Imperiofilia, a uno de los conceptos más imprecisos, manidos y científicamente estériles de la historia política de España: el llamado nacionalcatolicismo? Es decir, ¿cabría distinguir las motivaciones iniciales de Roca Barea de la lectura que de su obra hayan podido realizar sectores políticos 
concretos? Además, en su éxito hay algo evidente: su inmenso número de lectores abarca desde las posiciones políticamente más conservadoras hasta sectores ideológicos muy a la izquierda del PSOE. Sin duda, algo aporta la obra de Roca Barea que Villacañas no ha visto; algo que, además, desafía a la mayoría de los historiadores, incapaces - con todo nuestro oficio- de captar la atención de un inmenso público ajeno a nuestro gremio, de responder realmente a sus inquietudes.

\section{GÓMEZ DÍEZ, Francisco Javier}

Universidad Francisco de Vitoria (UFV) Madrid (España) 